\title{
IDENTIFICATION OF PSEUDO-NODAL POINTS ON THE BASIS OF PRECISE LEVELING CAMPAIGNS DATA AND GNSS
}

\author{
Michal BEDNARCZYK, Kamil KOWALCZYK * and Anna KOWALCZYK
}

University of Warmia and Mazury in Olsztyn, Faculty of Geodesy,

Geospatial and Civil Engineering, Heweliusza 12, 10-724 Olsztyn, Poland

*Corresponding author's e-mail: kamil.kowalczyk@uwm.edu.pl

\begin{tabular}{l} 
ARTICLE INFO \\
\hline Article history: \\
Received 29 May 2017 \\
Accepted 22 November 2017 \\
Available online 13 December 2017 \\
\hline
\end{tabular}

Keywords:

Hybrid models

Scale free network

Pseudo nodal points

\begin{abstract}
Four precise leveling campaigns has been carried out in Poland, and for several years there is a functioning system of permanent GNSS stations determining the height of network points. On the basis of these data, several variants of vertical crustal movements models have been developed (Wyrzykowski, 1987; Kowalczyk, 2005; Kontny and Bogusz, 2012). In order to develop a kinematic model of vertical crustal movements, one of the possibilities is an adjustment of the network formed simultaneously with the leveling data and GNSS stations data. The main problem is a need to identify fiducial points between the datasets. This problem can be solved by creation of coherent database containing attributes of both types of data and automatization of the joint point identification process. The article shows the results of such identification process, depending on the amount of data, on the example of the area of Poland.
\end{abstract}

\section{INTRODUCTION}

The data that can be used to develop the vertical crustal movements are: geological data (Zuchiewicz et al., 2007), seismic data (Romaniuk et al., 2014), leveling data (Gopwani and Scheidegger, 1971; Randjärv, 1968; Vaníček and Christodulidis, 1974; Wyrzykowski, 1971), tide gauge data (Tretyak and Dosyn, 2014), data from the GNSS stations (Vaniček and Krakiwsky, 1986; Kontny and Bogusz, 2012; Tran et al., 2013), Synthetic Aperture Radar data (SAR) (Bürgmann et al., 2000), Satellite Laser Ranging data (SLR) (Pearlman et al., 2002) or Very Long Baseline Interferometry (VLBI) (Campbell, 2000).

Each of mentioned methods is characterized by different factors such as: operating periods, accuracy, processing methods, temporal and spatial resolution and reference systems. This makes, that the use of such data for the development of vertical crustal movements is not an easy task.

In the literature most commonly combined data are: tide gauge data, leveling data and data from GNSS stations. They are developed as mathematical models (e.g. interpolation (Vestøl, 2006) or as geophysical models (Lambeck et al., 1998). As it was described in (Ågren and Svensson, 2007), a basic problem with a mathematical model is that it is uncertain how the data should be interpolated. In (Kowalczyk and Rapiński, 2017) it was shown, that the use of robust network adjustment of vertical movements with GNSS data, gives a good assessment of the quality of used material.

During adjustment, it is assumed that neighboring GNSS stations form a network of connections between which, the unadjusted vertical movement is determined. Then, this network is adjusted with the accepted one or more fixed points with known vertical speed, e.g. tide gauge point. This network can be further developed with GNSS data as well as leveling data. The basic problem in this aspect is to define common points between networks created independently on the basis of both (different) types of data. Therefore, in the article, it is argued that there are points which, under specific assumptions, can serve as shared points (pseudo-nodal points).

The purpose of this article is to examine the identification possibility of such points using mathematical algorithms and the scale-free networks theory.

In 2014, adjustment of the precision leveling network with respect to the Amsterdam tide gauge was carried out, based on the adjusted points of which were determined in the European adjustment process based on leveling data from 14 countries. Measurements were reduced to a 2000 epoch using the NKG2005LU vertical movement model (Ågren and Svensson, 2007). The calculations assume that the velocity of vertical movements is constant and linear. For a detailed description of the development of the EVRF2007 system, see (Sacher et al., 2008). 
For Poland the value of the vertical crustal movement at $-2 \mathrm{~mm} /$ year was assumed (Ågren and Svensson, 2007), based on the movement determined on a small sample of only four GPS stations. As a consequence of such approach, some local differences between PL-EVRF2007 heights and the predicted values based on regional vertical movements of the Earth's crust might occur (Fig. 1).

In Figure 1 it can be seen that the obtained height differences show deviations from the quasi constant difference by several centimeters. This is due to the use of the global crustal vertical movement model in calculations. Taking into account the time of the last precision leveling campaign in Poland (1997-2003) and the development of GNSS techniques, one can expect that another leveling campaign (the average interval between subsequent campaigns is approximately 20 years) is a big question mark, despite the announcements, that it will happen in 2020 (http://docplayer.pl/28302758-Podstawowa-osnowawysokosciowa-grawimetryczna-i-magnetyczna-ocena-stanui-prognozy-rozwoju.html). It follows that the benchmarks heights of the new PL-EVRF2007-NH have become obsolete at the time of its introduction. The solution for this problem may be the development of a new vertical crustal movements model basing on several previous leveling campaigns (Kowalczyk and Rapiński, 2013; Kowalczyk and Rapiński, 2017), on GNSS station data (Kowalczyk and Rapiński, 2017) or on hybrid data (leveling data and GNSS stations data). Developing a credible model of vertical crustal movements from GNSS stations data will allow for updating this system by introducing a correction to the elevation of the geodetic warp or correction to the elevation due to the vertical crustal movements. In general, the height update formula in the selected $\mathrm{k}$ period, without adjustment, may take the form:

$H\left(t_{k}\right)=H\left(t_{0}\right)+v\left(t_{k}-t_{0}\right)$

where $H$ denotes the height of the same point in epoch 0 and epoch $k$, and the product of crustal movement speed $v$ and time interval $\left(t_{k}-t_{0}\right)$ denotes the correction. The correction due to the vertical crustal movements can also be made at the re-adjustment stage by adding it to the measured height differences $\Delta h_{i j, k}$ :

$\Delta h_{i j, k}=\Delta h_{i j, 0}+v_{i j}\left(t_{k}-t_{0}\right)$

The variant of the correction usage as well as the choice of the appropriate adjustment method depends on the needs of conducted research on deformation as well as the national geodetic service. Regardless of the variant, it is important that the vertical velocity used is reliable and provides the correct accuracy. Starting from the general assumption that vertical movement is related to a point on the Earth's surface:

$$
\Delta h_{i j, k}=H_{j}-H_{i}+V_{j}\left(t_{k}-t_{0}\right)-V_{i}\left(t_{k}-t_{0}\right)
$$

It is possible to move from the aproximated designation of this motion to methods relying on the determination of vertical movement based on multiple measurements of the height differences between benchmarks and the subsequent adjustment of thus formed vertical motion network.

Height differences between permanent GNSS stations can be treated the same way as height differences between geodetic benchmarks. If these differences are determined in several epochs and connections between stations are defined, they also can establish a vertical crustal movement network, which can be adjusted. This analogy allows for simultaneous adjustment of both types of networks and gives the possibility for additional credibility evaluation of elaborated crustal movements model from GNSS stations data. However it requires the determination of shared points (Kowalczyk K., 2015) in both networks. So far in Poland, analysis and evaluation of measuring data from four precision leveling campaigns in Poland have been carried out in terms of their use to develop a model of vertical crustal movements as a triple and quadratic leveling grid, including definition of a formula for calculating the error of unadjusted vertical motion on line or segment of double leveling (Kowalczyk and Bednarczyk, 2009; Kowalczyk and Rapiński, 2013). The problem of simultaneous adjustment of vertical motion networks created on the basis of measurement data from the precision leveling campaigns and data from GNSS permanent stations, together with the procedure for the development of vertical crustal movements based on GNSS stations data (Kowalczyk K., 2015), has been defined. The adjustment of vertical relative movement network from the GNSS stations data has been conducted, including several adjustment variants, assuming different points in the network as fixed speed points (Kowalczyk K., 2015; Kowalczyk and Rapiński, 2017). The selection of these points was determined by their location (the center of the network, the proximity of the mareograph). The above criteria are not sufficient to define the appropriate shared points in vertical movement networks from leveling data and GNSS stations data. The problems of combining leveling data and GNSS stations data (Kowalczyk K., 2015) have been identified to develop a model of vertical movements of the Earth's crust:

- different reference systems;

- different measurement methods;

- different expected accuracies of vertical crustal movements; ;

- lack of shared points;

- different measuring epochs;

- different methods of measurement results adjustment;

- $\quad$ various measurement intervals; 

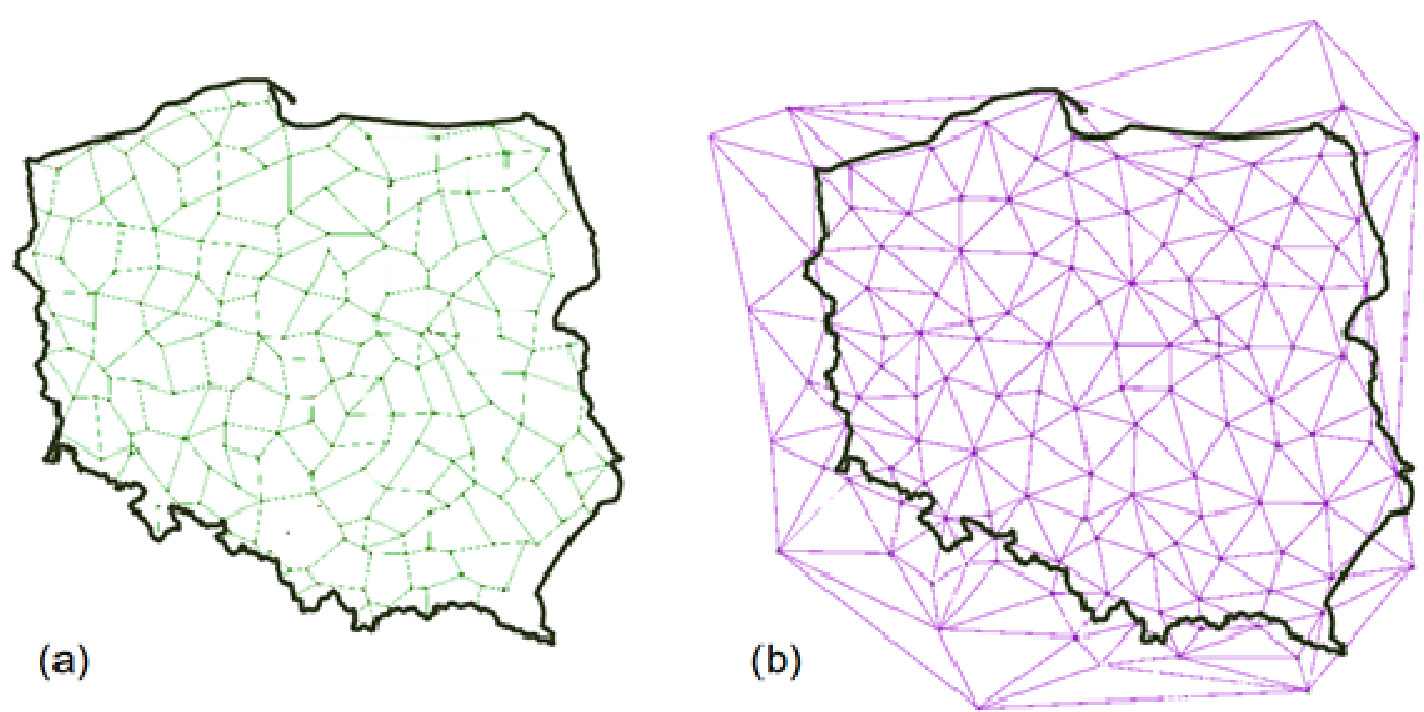

Fig. 2 Vertical crustal movement networks (a) from leveling data, (b) on the basis of permanent GNSS stations locations.

To perform calculations the leveling data from previously created database (Kowalczyk and Bednarczyk, 2009; Kowalczyk and Rapiński, 2017; Kowalczyk et al., 2011) and ASG EUPOS Polish network data were used (Kowalczyk et al., 2014). Both these sets were proposed to be joined and used as vertical crustal movement network (Kowalczyk K., 2015; Kowalczyk, 2005; Kowalczyk and Rapiński, 2017).

Thus, two kinds of network might be defined (Fig. 2):

- Vertical crustal movement network from leveling data - this is the double leveling network, where vertical movement between nodal benchmarks is calculated.

- Vertical crustal movement network from permanent GNSS stations data - this is the network created on the basis of connections between GNSS stations, chosen artificially. Then, vertical movement was calculated between stations connected this way.

In this paper, authors decided to propose a new, different way of identification of common points between networks mentioned above, to join them into one vertical crustal movement network.

The selection algorithm is based on the analysis of spatial relationships between nodes. Points from different nets, which are close enough to each other, can be treated as if they have the same vertical movement value, so they can be considered as shared points between networks. In this article, a pair of close range points belonging to different networks is referred to as pseudo-nodal point. The proposed algorithm consists of three stages:

1. Determination of pseudo-nodal points basing on defined criterion.

This step allowed for identification of pairs: leveling point - GNSS station in other words: pseudo-nodal points in both networks.

2. Analysis of the set of points determined in step 1 using the scale-free networks theory.

In this step it was determined, which of pseudonodals selected before, has the biggest impact on the network.

3. Spatial analysis of point location in relation to geological conditions.

In this step some examples of spatial analyses were shown. According to author's opinion it is important to broaden the scope of consideration and analyze the network nodes location in other terms than the network construction only. The geological conditions of the nodes locations seem to be the most influential. That is why these examples have been developed using geological maps.

As a result, the first version of point selection algorithm for adjustment of hybrid vertical crustal movement networks for Poland was obtained.

\section{DETERMINATION OF ALL PSEUDO-NODAL POINTS IN THE NETWORK \\ DEFINING THE DISTANCE CRITERION}

The distance between leveling network nodal points and GNSS permanent stations is not a constant value. It varies from hundreds of meters to several kilometers. How can it seem, points located very near each other, should have very similar values of vertical crustal movements. To estimate the maximum distance between nodal points and GNSS permanent stations, an analysis of unadjusted vertical movement change on selected leveling lines has been conducted. The analysis was based on the leveling data of the double leveling network. For this purpose 26 fragments of the double leveling lines were used in different parts of Poland. The maximum length of the 
Table 1 The mean values of the unadjusted vertical displacement.

\begin{tabular}{lllllllllll}
\hline $\mathbf{k m}$ & 1 & 2 & 3 & 4 & 5 & 6 & 7 & 8 & 9 & 10 \\
$\mathbf{m m} / \mathbf{y}$ & 0.09 & 0.09 & 0.08 & 0.10 & 0.08 & 0.06 & 0.08 & 0.07 & 0.13 & 0.13 \\
\hline
\end{tabular}

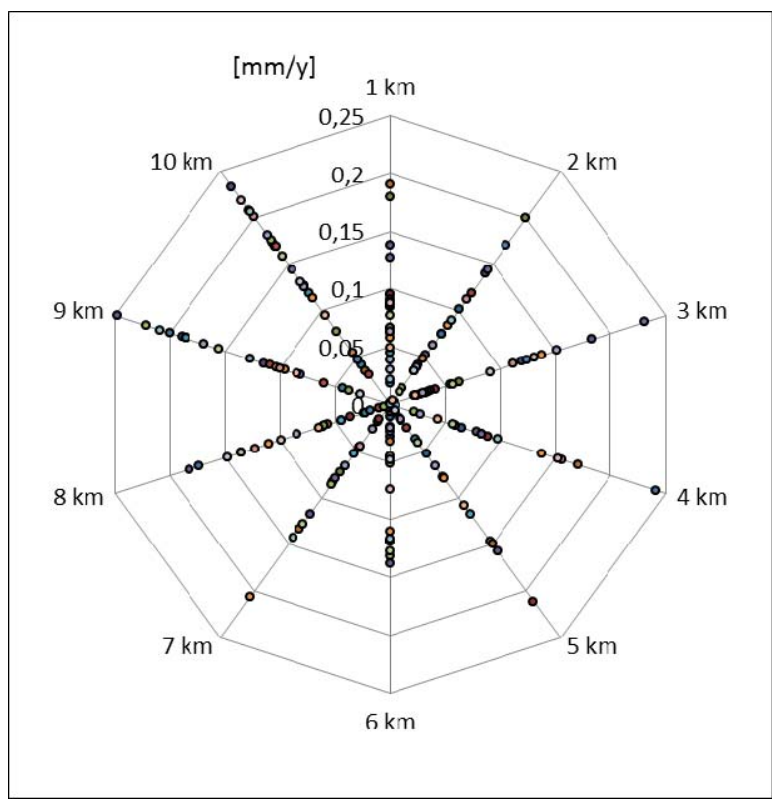

Fig. 3 Unadjusted vertical movement values (absolute value) with $1 \mathrm{~km}$ interval on chosen double leveling line segments.

line does not exceed $10 \mathrm{~km}$ and contains from a few to a dozen intermediate points. Vertical movement was calculated between each intermediate point and the nodal point of a given line. The results were compiled in intervals of $1 \mathrm{~km}$. The results are shown in Figure 3.

Obtained values vary between $\pm 0 \mathrm{~mm} / \mathrm{y}$ and $\pm 0.25 \mathrm{~mm} / \mathrm{y}$. It seems that there is no relationship between the vertical movement value and the increase of analyzed distance. The mean values of the unadjusted vertical displacement are shown in the table below (Table 1).

Based on the analysis, points from double leveling network and from GNSS stations (ASG EUPOS) network that are within the distance not exceeding $10 \mathrm{~km}$, can be considered as corresponding to the same nodal point (pseudo-nodal point).

\section{SPATIAL ANALYSIS ON THE BASIS OF DETERMINED CRITERION}

As mentioned, for analysis the database of four precise leveling campaigns in Poland (Kowalczyk et al., 2011) and ASG EUPOS (GNSS) stations locations were used. The goal of this step was to identify pseudo-nodal points in both networks, which might be possible to be used as shared points. The analysis was performed using QGIS system.

The data about leveling points were obtained from the database of four precise leveling campaigns in Poland (Kowalczyk et al., 2011) previously created by the authors on the basis of many various sources, among of which analog paper catalogs and datasheets were. Data structure for every leveling campaign was different, depending on the time of creation. Creation of consistent database required creation of one database schema. The database is now implemented in relational database management system. This helps to automate many operations, which previously could not be done. This allowed to extract data about leveling points from campaigns number 3 and 4 and to import them into QGIS for further analysis. In QGIS two point layers in EPSG: 2180 coordinate system were loaded. They are described below.

"GNSS stations", with attributes:

- NR - GNSS station name

- $\mathrm{X}-\mathrm{X}$ coordinate,

- $\mathrm{Y}$ - y coordinate.

"Leveling points", with attributes:

- NR - leveling point number

- $\mathrm{X}-\mathrm{x}$ coordinate,

- $\mathrm{Y}$ - y coordinate.

First, the distances from each GNSS station to the nearest leveling point were calculated and saved as additional attributes in "GNSS stations" layer:

- HubName - the number (name) of the nearest leveling point

- HubDist - the distance to the nearest leveling point

As a result 124 pairs of nodes were identified. The distance between GNSS stations and the nearest leveling points ranged from $98 \mathrm{~m}$ to $149 \mathrm{~km}$. Then, only distances less than $10 \mathrm{~km}$ were filtered out, according to earlier assumptions. In the resulting set 54 pseudo-nodal points were found. Only one pseudonodal point has a distance value about $10 \mathrm{~km}$ between points, the rest of them were with distance less than $6 \mathrm{~km}$ (Fig. 4).

Because the analysis was performed on a layer containing only GNSS stations data, it was necessary to supplement it with the data of the leveling points. As a result of the merger, a dataset containing GNSS data and leveling points in their immediate vicinity was created. Its structure is shown in Figure 5.

It can be said that the dataset of pseudo-nodal points was obtained as the result. Because it contains point names, it can easily be extended to include additional data about them by joining it with tables from previously created database of four precise leveling campaigns in Poland (Kowalczyk et al., 2011). This gives the opportunity to perform further analyses and calculations. This dataset was then subjected to analyses, described later in this article, based on the theory of scale-free networks. Thanks to that it was possible to identify the most significant points of both networks. 


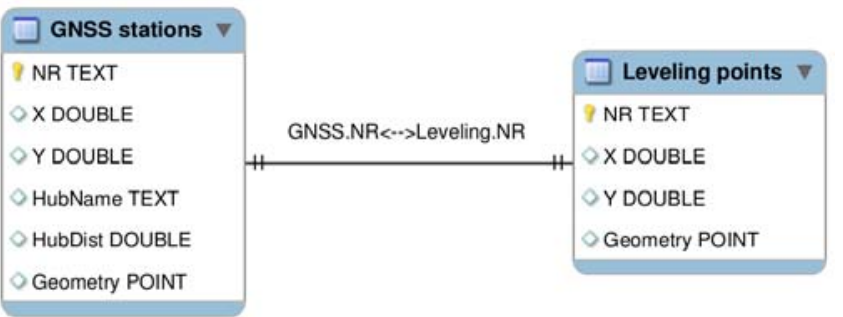

Fig. 5 Merged layers data.

\section{NETWORK ANALYSIS}

Network structures understood as systems of nodes and connections occur in the real world very often. These connections may be physical in nature, or they may indicate specific dependencies between the nodes (Kowalczyk A.M., 2015). Until the 1990s, networks were described as complex structures, which were spontaneously created without the explicit organization, they were called random networks (Erdös and Rényi, 1960). The development of information technology (IT) and the creation of databases about networks have allowed more detailed research into their structure. This allowed a number of specific features of some complex networks that were not taken into account before to be identified. In the end of the twentieth century research on the Internet as a new network structure was carried out, and continues to grow very dynamically in a spontaneous way (Barabási and Albert, 1999; Barabási, 2009). It was discovered that the distribution of nodes in the Internet does not correspond to the normal distribution, which characterizes random networks. Such types of networks are called scale-free networks. This discovery directed the researchers to other fields, and it turned out that such distribution of nodes is typical not only for Internet, but many other social, technological or biological phenomena can be also researched this way. Any phenomenon that has a network structure, such as geodetic networks, roads or even terrorists links, can be analyzed either as a scale-free or random networks, which gives the ability to find out their properties.

The general characteristics of random networks and scale-free networks are shown in Table 2.

The above-described networks have their numerous modifications, extensions and generalizations (Kasprzyk, 2010). Random and scalefree networks may have some similarities due to their construction - modularity, hierarchy, and may have both features at once (Kowlaczyk, 2017). Determining if the network is scale-free or random, it is very important to understand the behavior of these structures in the presence of certain behaviors. For the purposes of this article, particular attention has been paid to those network properties that address susceptibility to structural change.
Table 3 Nodes and links in vertical crustal movement network formed from GNSS stations data.

\begin{tabular}{rr}
\hline Number of links & Number of nodes \\
\hline 1 & \\
2 & 3 \\
3 & 20 \\
4 & 36 \\
5 & 42 \\
6 & 14 \\
7 & 8 \\
8 & 1 \\
9 & \\
10 & \\
\hline
\end{tabular}

\section{THE ANALYSIS OF VERTICAL CRUSTAL MOVEMENT NETWORK FROM GNSS STATIONS DATA}

In the network of vertical crustal movements formed from GNSS stations data, the nodes are the GNSS stations of the Polish ASG-EUPOS network (Fig. 2b), while the connections are the speeds of height differences between two GNSS stations.

Among 124 nodes as a whole, the network has 20 nodes with 4 connections, 36 with 5 connections and 42 with 6 connections. These nodes represent $80 \%$ of their total number. There is also one strong node with 9 connections. The detailed number of nodes with specified connections is shown in Table 3 .

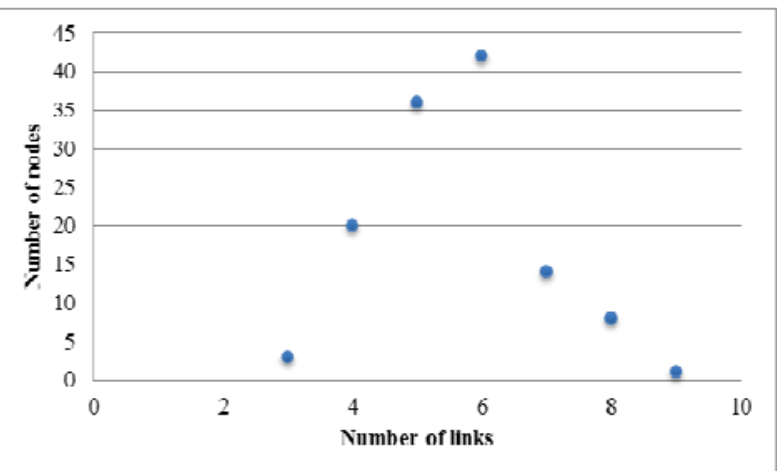

Fig. 6 The degree distribution of the vertical crustal movement network in GNSS stations data as a random network which follows a bell curve.

The distribution of nodes and connections in the analyzed network (Fig. 6) showed that most nodes have approximately the same number of connections. Nodes with a much larger number of connections are not present. This demonstrates the random nature of this network, despite the connections not being created in a random way. As is clear from the properties of random networks, this network does not have nodes which may be qualified as centers. 
Table 4 Nodes and links in vertical crustal movements network formed from leveling data.

\begin{tabular}{cc}
\hline Number of links & Number of nodes \\
\hline 1 & 29 \\
2 & 118 \\
3 & 66 \\
4 & 21 \\
5 &
\end{tabular}

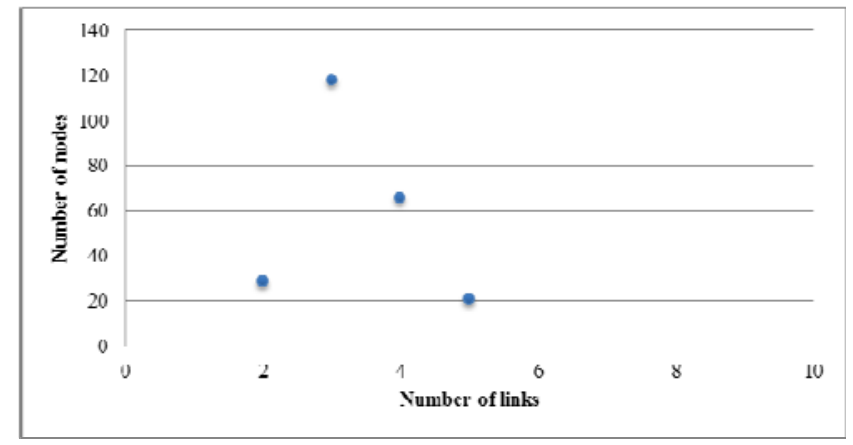

Fig. 7 The degree distribution of the vertical crustal movement network created from leveling data as a random network which follows a bell curve.

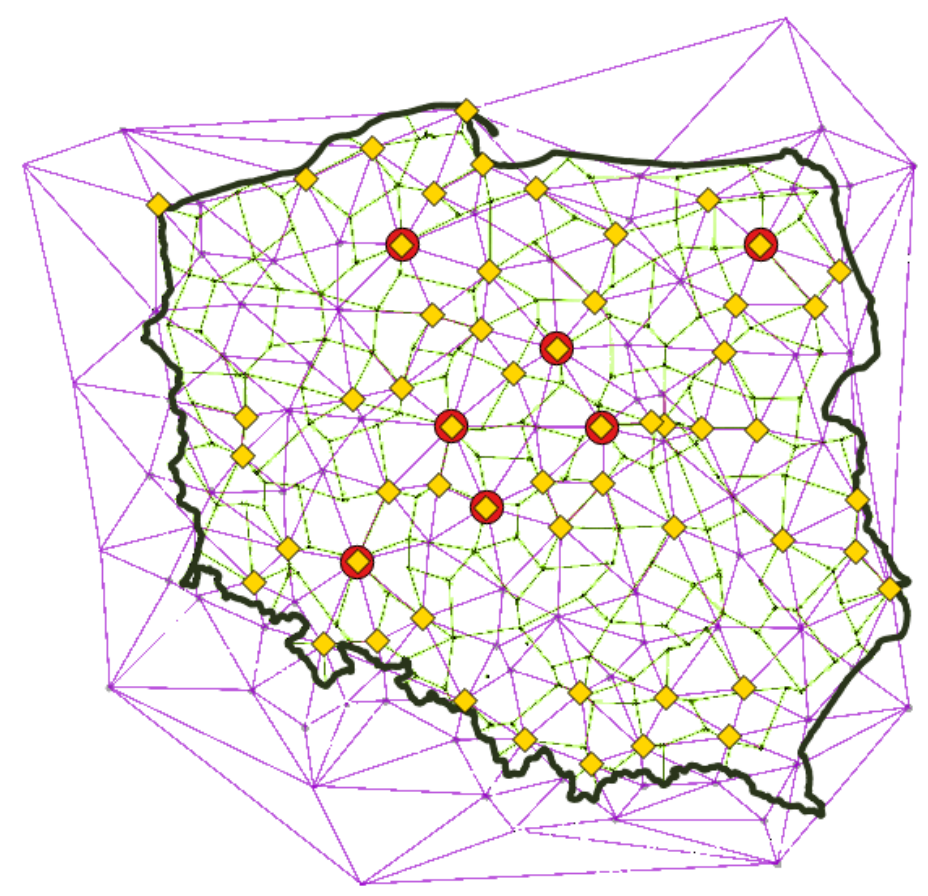

Fig. 8 The network created from combination of GNSS and leveling networks. Squares shared points, circled squares - nodes with the highest number of connections ("the strongest" nodes).

\section{THE ANALYSIS OF VERTICAL CRUSTAL MOVEMENT NETWORK FROM LEVELLING DATA}

In the vertical crustal movement network formed from the leveling data, the nodes are the node leveling benchmarks and the connections are connections the speeds of height differences on the leveling lines (Fig. 2a).

The vertical crustal movement network formed from the leveling data consists of 234 nodes. 118 nodes have 3 connections and 66 nodes have four connections. These nodes represent $90 \%$ of total number. The detailed number of nodes with specified connections is shown in Table 4.

As in the vertical crustal movement network created from the GNSS stations data, despite the lack of randomness in connections creating process, the network from the leveling data is random (Fig. 7).
It should be understood that these both networks are characterized by a normal distribution. This situation suggests that if a randomly selected node is removed, these networks will break into smaller, separately functioning network structures. There are no central nodes here as well. Therefore, there are no nodes of strategic importance in these networks, the destruction of which would result in a complete disintegration of the network structure and thus its disfunctionality.

\section{THE ANALYSIS OF VERTICAL CRUSTAL MOVEMENT NETWORK CREATED FROM COMBINATION OF GNSS \\ AND LEVELING NETWORKS}

The network created from combination of GNSS and leveling network consists of 234 nodes (Fig. 8). 
Table 5 Nodes and links in both network structures: network

\begin{tabular}{rr}
\hline $\begin{array}{c}\text { Number } \\
\text { of links }\end{array}$ & $\begin{array}{c}\text { Number } \\
\text { of nodes }\end{array}$ \\
\hline 1 & \\
2 & 25 \\
3 & 97 \\
4 & 59 \\
5 & 36 \\
6 & 25 \\
7 & 8 \\
8 & 19 \\
9 & 12 \\
10 & 17 \\
11 & 4 \\
12 & 2 \\
13 & 1 \\
\hline
\end{tabular}

The nodes are both: GNSS stations and leveling benchmarks. Connections, according to the network type, are height differences between stations or benchmarks. Some nodes may act as shared points between GNSS and leveling network. There are 54 such nodes (Figs. 4 and 8) identified and described in section above "Determination of all pseudo-nodal points in the network".

In the analyzed network, there are 97 nodes with 3 connections and 59 nodes with 4 connections. But some of them has many more connections then average. There are 4 nodes with 11 connections, 2 nodes with 12 connections and 1 with 13 connections. The detailed number of nodes with specified connections is shown in Table 5.

The degree distribution of analyzed network shows its scale-free character (Fig. 9). It means that, there are center nodes with far more connections then average. These center nodes are very important in the network structure and they are also shared points between both network types (GNSS and leveling network). There are 7 such nodes and they are depicted in Figure 8. It gives information, that only 7 of 54 shared nodes are the most important. This may allow a decision about limiting the number of shared points to be done. It is of a big importance especially in the networks with hundreds of nodes.

\section{SPATIAL ANALYSIS OF POINT LOCATION IN RELATION TO GEOLOGICAL CONDITIONS}

The adjustment of vertical crustal movement network requires the selection of appropriate points, not affected by the influence of additional disturbing factors. Every additional error of pseudo-nodal point will be transferred onto entire network, according to the errors distribution theory. Therefore, when the set of points is already determined and evaluated from the network quality point of view, it can be now analyzed in other aspects. In case of examining the vertical crustal movements, the geological conditions

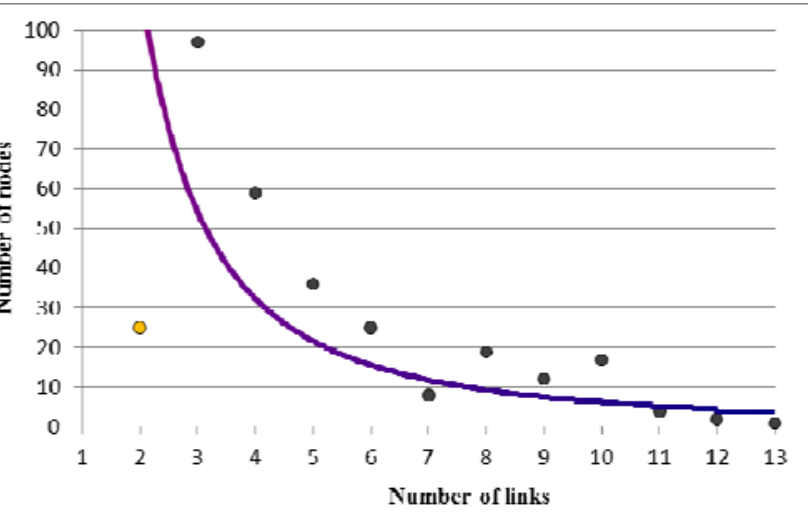

g. 9 The degree distribution of both networks structures as a scale-free network which follows the power function.

of the areas on which the individual points are located are important. Geological maps provide information about geological structure of the ground. This information may help to consider, whether a leveling point is located on solid ground or maybe its vertical movement is distorted by factors not connected with the Earth crust. For example - maybe there's a working coal mine near the point location, landslide or another cause of ground instability Such situation may have influence on the adjustment, and such point should be low-weighted or omitted in the calculation process.

Such analysis is possible to perform with the use of GIS system and appriopriate WMS services or other maps. WMS means Web Map Service and is a way of distributing and sharing spatial data without a special need to download the whole dataset. In case of this paper, WMS services shared by Polish Geological Institute were used. Figure 10 shows the location of individual points on the geological map of Poland. One can read the general geological characteristics of the areas where the points are located. More detailed information can be obtained using a larger scale (1:50 000) geological map, as it is shown in Figure 11, where two points are located on different geological areas. It is also possible to consider points located near exploited mining areas (Fig. 12) or landslides (Fig. 13).

The authors of this article, are not geologists, and only want to show a few examples of the use of this data, thus indicating the possibility of more detailed examination of individual points in terms of the geology of the areas on which they are located. However, detailed analyses and a fair assessment of the situation require consultation of geologists, which is planned in the near future.

\section{CONCLUSIONS}

The development of new measurement techniques from which data can aid the processes of 


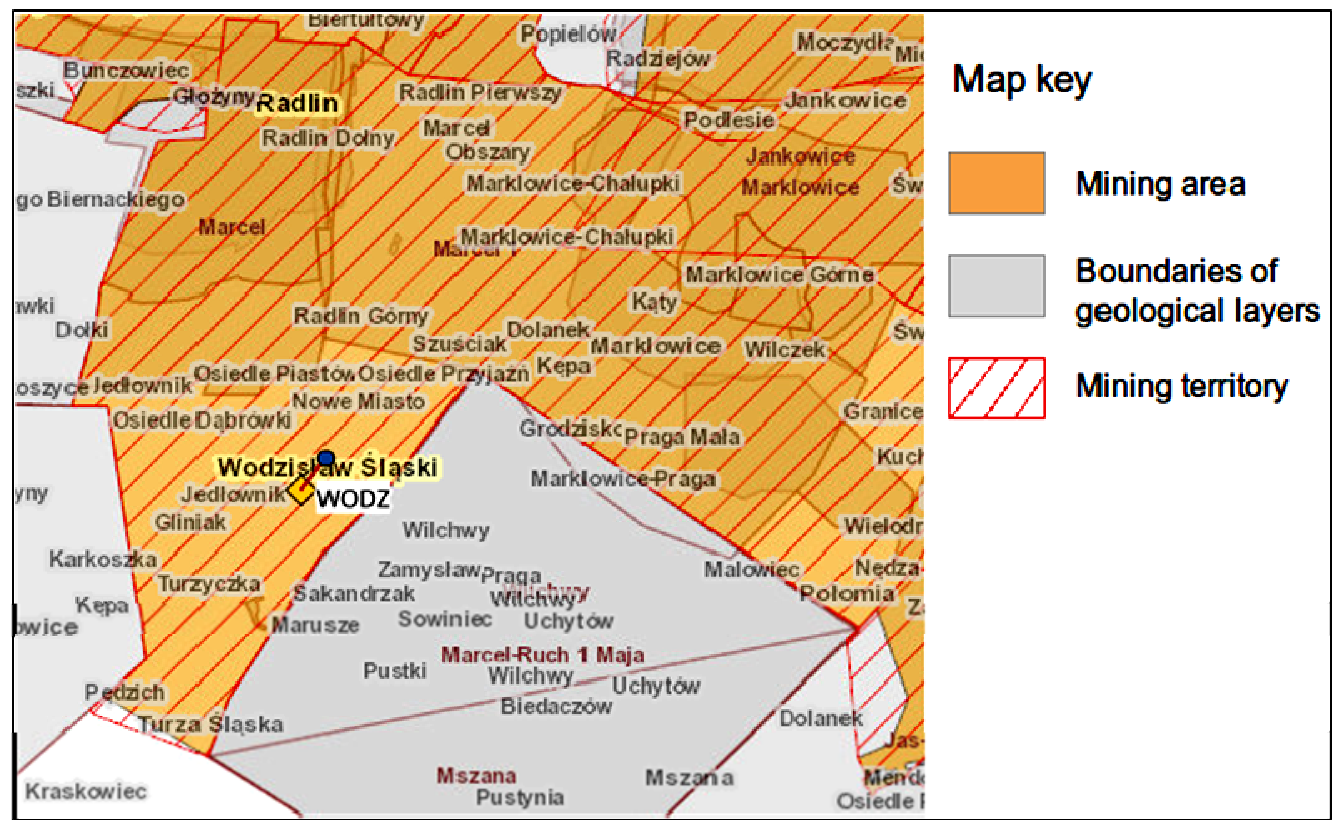

Fig. 12 Pseudo-nodal point on the exploited mining area "Radlin". Source: own elaboration on the basis of WMS service: http://cbdgmapa.pgi.gov.pl/arcgis/services/midas/MapServer/WMSServer.

determining the vertical movements of the Earth's crust makes it necessary to undertake scientific work on new methods of combining these data and developing hybrid models.

The article presents the possibility of combining two types of data: leveling and GNSS permanent stations. Each of them creates an independent network of links. In order to connect them and simultaneously adjust, the common nodes in both networks were determined using the distance criterion. The analysis showed that the points in $10 \mathrm{~km}$ distance, belonging to different networks can be treated in further elaborations as one point belonging to both networks. Approximately 50 potential joint points were identified in the tested networks with over 350 points taken for analysis.

The algorithm described in this article might be used to choose the appropriate shared points for vertical crustal movement network adjustment. Pseudo-nodal points, defined and chosen in first step, were next filtered using the scale-free network theory. This is also an innovative approach which hasn't been used yet in this kind of networks structures.

Network analyzes have shown that the distribution of connections in both networks is random. Linking both independent networks into one network by identifying common points changes their character from random to scale-free network. This means that in the combined structure there are network centers that have the greatest impact on the network. This reduces the number of shared points (in tested networks from 50 to 7) and reduces the number of points that are subjected to the further analysis, for example with geological data usage.
Performing spatial analysis on the basis of geological maps also seems to be a good idea. This way may increase the certainty of choosing the right points for adjustment calculations. Choosing such points in large networks is difficult, so having a good method which allows for increasing the number of points is very useful.

The next step in this research will be to perform an alignment using the described algorithm. However, at this moment the cooperation with geologists is required. The results of the study and the further conclusions will be published in the next article.

\section{REFERENCES}

Ågren, J. and Svensson, R.: 2007. Postglacial land uplift model and system definition for the new Swedish Height System RH 2000. Gävle, LMV-Rapport, 4, 124 pp.

Barabási, A.L.: 2002, Linked: How everything is connected to everything else and what it means for business, science and everyday life. Plume Editors.

Barabási, A.L.: 2009, Scale-free networks: a decade and beyond. Science, 325, 412-413.

Barabási, A.L. and Albert, R.: 1999, Emergence of scaling in random networks. Science, 286, 509-512.

Bürgmann, R., Rosen, P.A. and Fielding, E.J.: 2000, Synthetic aperture radar interferometry to measure Earth's surface topography and its deformation. Ann. Rev. Earth Planet. Sci., 28, 1, 169-209. DOI: 10.1146/annurev.earth.28.1.169

Campbell, J.: 2000, Very Long Baseline Interferometry - a high precision tool for geodesy and astrometry. C. R. Acad. Sci. Paris, Série IV - Physics 1(10), 1255-1265. DOI: 10.1016/S1296-2147(00)01139-2

Erdös, P. and Rényi, A.: 1960, On the evolution of random graphs. Publ. Math. Inst. Hung. Acad. Sci, Ser. A5, $17-61$. 
Gopwani, M.V. and Scheidegger, A.E.: 1971, Contemporary and recent vertical crustal movements and their interpolation. Ann. Geophys., 24, 1, 2-27. DOI: $10.4401 /$ ag-5150

Kasprzyk, R.: 2010, The simulator of malwares spreading in telecommunication networks. Symulacja w Badaniach i Rozwoju, Polskie Towarzystwo Symulacji Komputerowej 1(2), 139-149, (in Polish).

Kontny, B. and Bogusz, J.: 2012, Models of vertical movements of the Earth crust surface in the area of Poland derived from leveling and GNSS data. Acta Geodyn. Geomater., 9, 3(167), 331-337.

Kowalczyk, K.: 2005. Determination of land uplift in the area of Poland. 6th International Conference Environmental Engineering, 1 and 2, 903-907.

Kowalczyk, K.: 2008, Vertical crustal movements in Poland for instance any fragment three levelings network. 7th International Conference "Environmental Engineering", 3, 1354-1358.

Kowalczyk, A.: 2017. The analysis of networks space structures as important elements of sustainable space development. 10th International Conference „Environmental Engineering“

Kowalczyk, A.M.: 2015, The use of scale-free networks theory in modeling landscape aesthetic value networks in urban areas. Geodetski Vestnik, 59, 1, 135-152. DOI: 10.15292/geodetski-vestnik.2015.01.135-152

Kowalczyk, K.: 2015, The creation of a model of relative vertical crustal movements in the Polish territory on the basis of the data from active geodetic network EUPOS (ASG EUPOS). Acta Geodyn. Geomater., 12, 3(179), 215-225. DOI: 10.13168/AGG.2015.0022

Kowalczyk, K. and Bednarczyk, M.: 2009, Relational database of three precise leveling campaigns in Poland. Tech. Sci., 12, 145-164. DOI: 10.2478/v10022-009-0013-8

Kowalczyk, K., Bednarczyk, M. and Kowalczyk, A.: 2011, Relational database of four precise levelling campaigns in Poland. 8th International Conference „Environmental Engineering”, 1-3, 1356-1361.

Kowalczyk, K., Bogusz, J. and Figurski, M.: 2014, The analysis of the selected data from Polish active geodetic network stations with the view on creating a model of vertical crustal movements. 9th International Conference "Environmental Engineering", 22-12 May, 2014, Vilnius, Lithuania. Selected Papers. DOI: 10.3846/enviro.2014.221

Kowalczyk, K. and Rapiński, J.: 2013, Evaluation of levelling data for use in vertical crustal movements model in Poland. Acta Geodyn. Geomater., 10, 3(171), 401-410. DOI: 10.13168/AGG.2013.0039

Kowalczyk, K. and Rapiński, J.: 2017, Robust network adjustment of vertical movements with GNSS data. Geofizika, 34, 1, 45-65. DOI: 10.15233/gfz.2017.34.3

Lambeck, K., Smither, C. and Ekman, M.: 1998. Test of glacial rebound models for Fennoscandia based on instrumented sea- and lake-level records. Geophys. J. Int. 135: 375-387.

Pearlman, M.R., Degnan, J.J. and Bosworth, J.M.: 2002, The international laser ranging service. Adv. Space Res., 30, 2, 135-143.

DOI: $10.1016 / \mathrm{S} 0273-1177(02) 00277-6$

Randjärv, J.: 1968, The character and velocities of recent crustal movements in the Baltic regions. Recent crustal movements of the Earth, 3, USSR Acad. Sci., Moscow, 200-210.
Romanyuk, V., Smirnova, O., Babiy, L., Tretyak, K. and Sidorov, I.: 2014, Investigation of the interrelation between vertical movements of the crust and generalized seismic activity on the territory of Europe. EGU General Assembly 2014, Austria. Geophys. Res. Abstracts, 16, 11303.

Sacher, M., Ihde, J., Liebsch, G. and Mäkinen, J.: 2008, EVRF07 as realization of the European Vertical Reference System. Symposium of the IAG Subcommission for Europe (EUREF), Brussels, June 1821, 2008. Boll. Geod. Sci. Affini, 68, 1, 35-50.

Trần, Đ.T., Nguyễn, T.Y., Dương, C.C., Vy, Q.H., Zuchiewicz, W. and Nguyễn, V.N.: 2013, Recent crustal movements of northern Vietnam from GPS data. J. Geodyn., 69, 5-10. DOI: $10.1016 /$ j.jog.2012.02.009

Tretyak, K. and Dosyn, S.: 2014. Study of vertical movements of the European crust using tide gauge and GNSS observations. Reports on Geodesy and Geoinformatics, 97, 1, 112-131. DOI: 10.2478/rgg2014-0016

Vaníček, P. and Christodulidis, D.: 1974, A method for the evaluation of vertical crustal movement from scattered geodetic relevellings. Can. J. Earth Sci., 11, 5, 605610. DOI: 101139/e74-057

Vaniček, P. and Krakiwsky, E.: 1986, Geodesy: The Concepts, Elsevier, Amsterdam, $697 \mathrm{pp}$

Vestøl, O.: 2006, Determination of postglacial land uplift in Fennoscandia from leveling, tide-gauges and continuous GPS stations using least squares collocation. J. Geod., 80, 5, 248-258. DOI 10.1007/s00190-006-0063-7

Wyrzykowski, T.: 1971, Map of modern absolute speed of vertical movements of the surface of the Earth's crust in the area of Poland. Państw. Przeds. Wyd. Kartogr., Warszawa.

Wyrzykowski, T.: 1987, A new determination of recent vertical movements of the Earth's crust in Poland. J. Geodyn., 8, 2-4, 171-178. DOI: $10.1016 / 0264-3707(87) 90035-4$

Zuchiewicz, W.: 2000. Maps 1:500 000: Contemporary tectonic movements, tectonic movements in the Quaternary period and tectonic movements in the Quaternary period II. Unit nietektonicznostructural, In W. Maciejowski and R. Uliszak (eds.), Polish Atlas, Encyclopedia world geography, 11, Opress, Kraków, 29-30.

Zuchiewicz, W., Badura, J., and Jarosiński, M.: 2007. Notes on Polish neotektonic: some examples. Biuletyn Państwowego Instytutu Geologicznego, (425), 105127.

\section{Internet sources}

http://cbdgmapa.pgi.gov.pl/arcgis/services/kartografia/mgpb k1000k/MapServer/WMSServer

http://cbdgmapa.pgi.gov.pl/arcgis/services/kartografia/smgp 50k/MapServer/WMSServer.

http://cbdgmapa.pgi.gov.pl/arcgis/services/midas/MapServe r/WMSServer.

http://cbdgmapa.pgi.gov.pl/arcgis/services/geozagrozenia/so po obszary/MapServer/WMSServer.

http://www.asgeupos.pl/webpg/graph/img/ news/00202/2.1. pdf :20.08.2017

http://docplayer.pl/28302758-Podstawowa-osnowawysokosciowa-grawimetryczna-i-magnetyczna-ocenastanu-i-prognozy-rozwoju.html :25.08.2017 

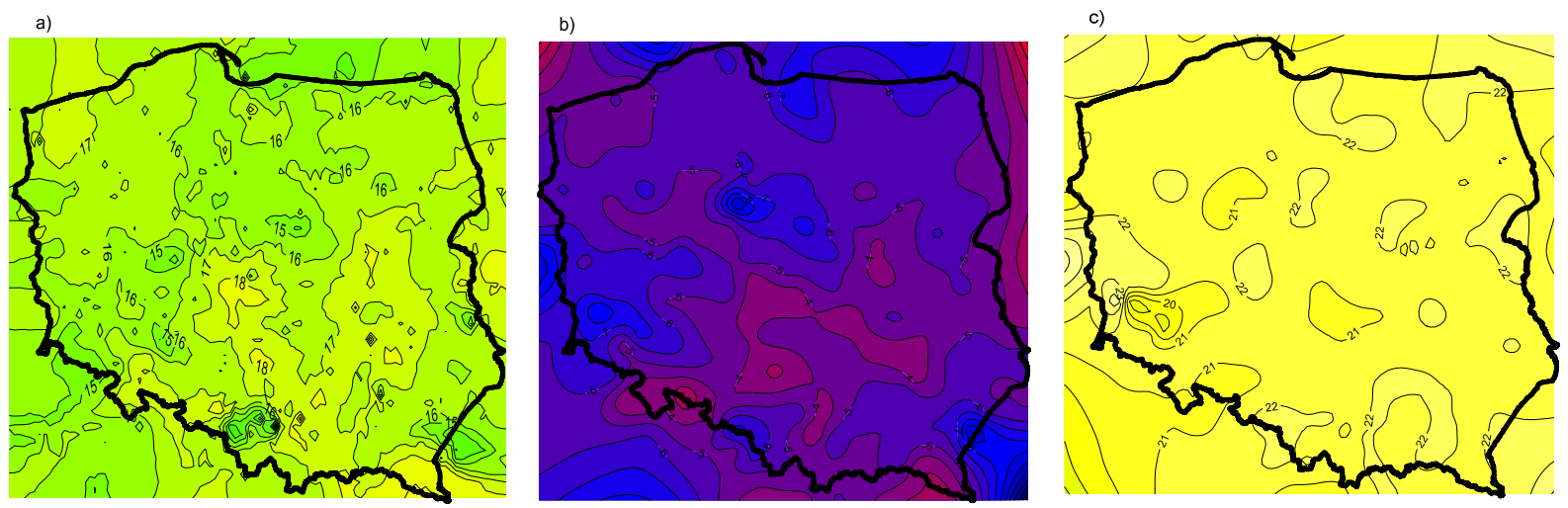

[cm] $\begin{array}{llllllllllll}28 & 24 & 20 & 16 & 12 & 8 & 4 & 0 & -4 & -8 & -12 & -16\end{array}$

Fig. 1 a) Aproximate normal heights differences $(\mathrm{H})$ between PL-EVRF2007-NH and PL-KRON86- NH reference systems, b) predicted normal heights changes of KRONSZTADT 86 system for the 2000 epoch on the basis of vertical crustal movements in Poland, developed in (Kowalczyk, 2008) and c) normal heights differences between PL-EVRF2007-NH and KRONSZTADT 86 for the 2000 epoch on the basis of vertical crustal movements in Poland, developed in (Kowalczyk, 2008), the models were developed with $1 \mathrm{~cm}$ cutting using the smallest curvature interpolation.

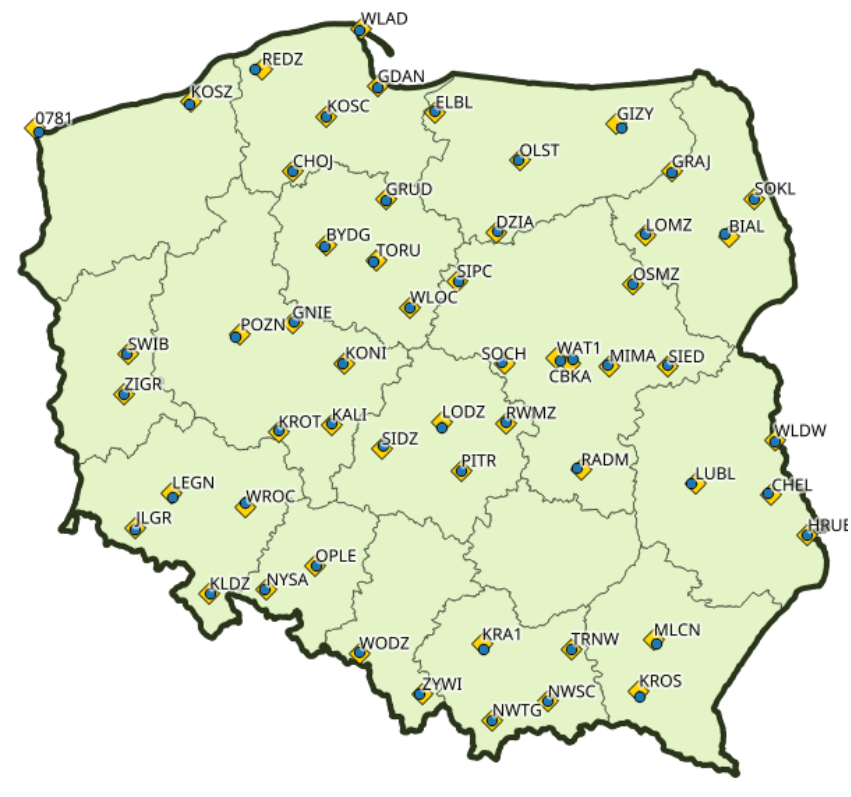

Fig. 4 Identified pseudo-nodal points.

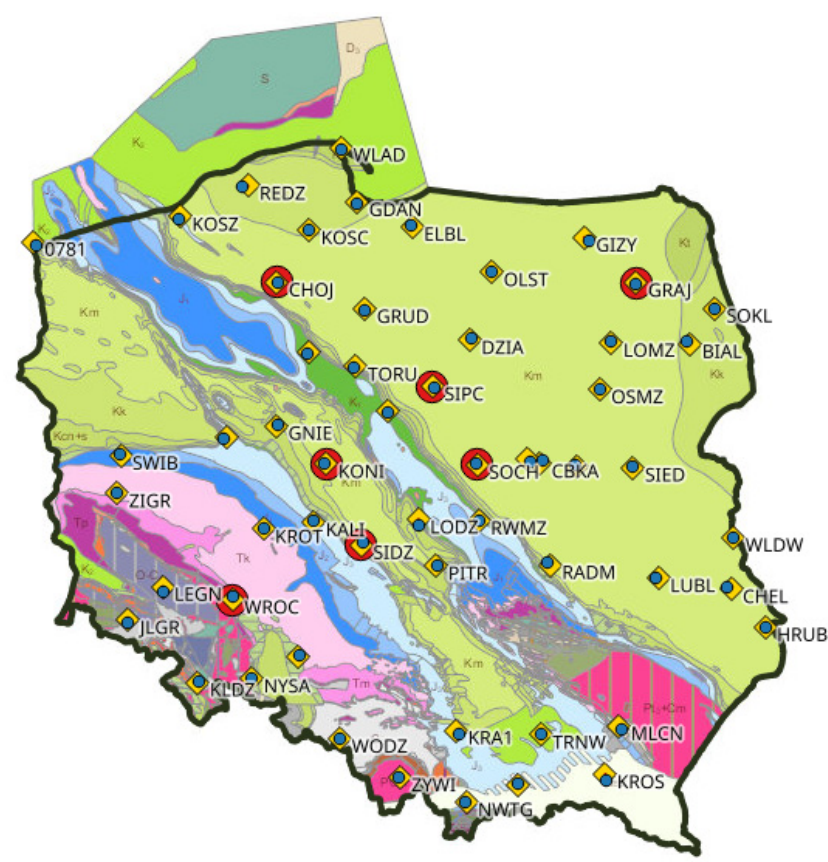

Fig. 10 All pseudo-nodal point on the geological map. Scale: 1:1 000000 .

Source: own elaboration on the basis of WMS service: http://cbdgmapa.pgi.gov.pl/arcgis/services/kartografia/mgpbk1000k /MapServer/WMSServer 
Table 2 The general characteristics of random networks and scale-free networks.

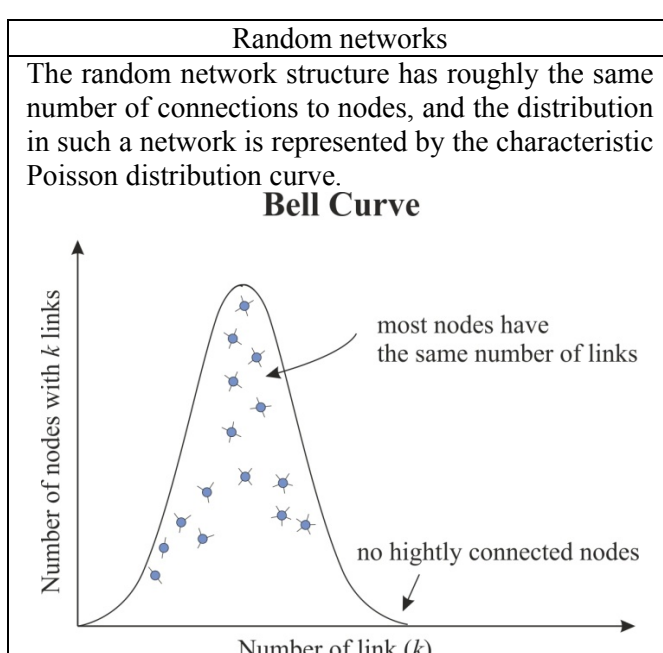

No centers (hubs) - nodes that have more connections than the average number of connections to nodes.

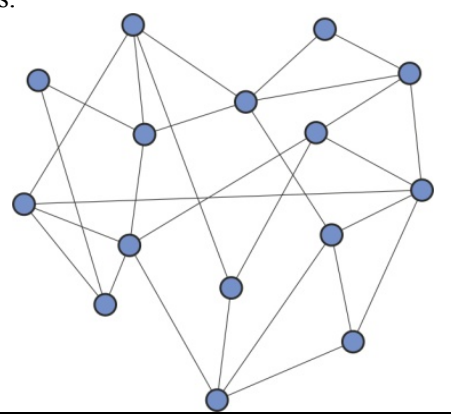

There is no preferential connection selection in a particular hierarchy.

Random cutoff (sometimes referred to as an attack on a node or nodes), that is, the permanent or temporary destruction of a given number of nodes, leads to break down of the whole network structure into smaller, separately functioning networks. The structure can be severely damaged.

Source: Own analysis based on (Kowalczyk, 2017; Barabasi, 2002).

with entire network structure. the entire network in active state.

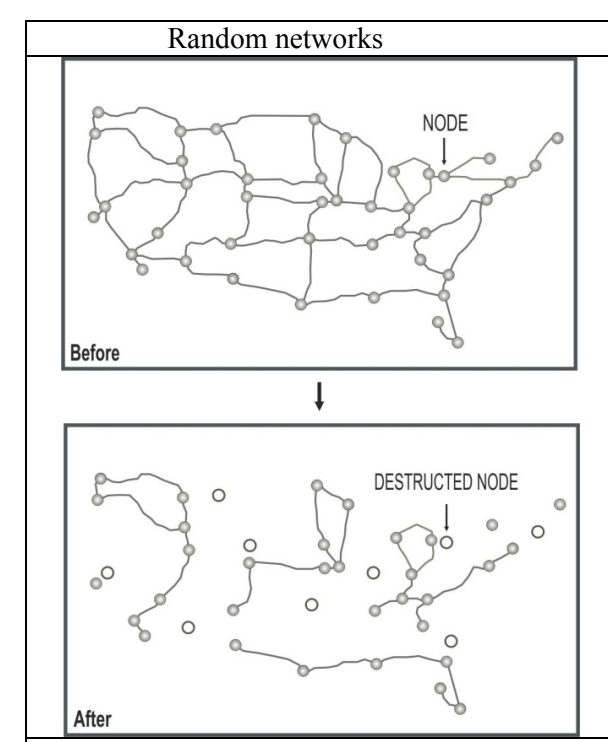

No centers in the network structure.

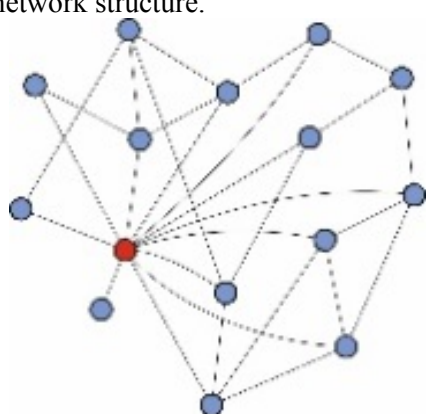

There is a preferential selection of connections in a given hierarchy - when a new node appears, it tends to bind to nodes with a high number of bindings, and this favorable feature makes the nodes more and more interconnected in opposition to their neighboring nodes with fewer connections. Resilience to random attacks - An accidental attack on a node does not have such a devastating impact on scale-free network as it has on random network Thanks to the heterogeneous structure, there are always connections that continue to hold

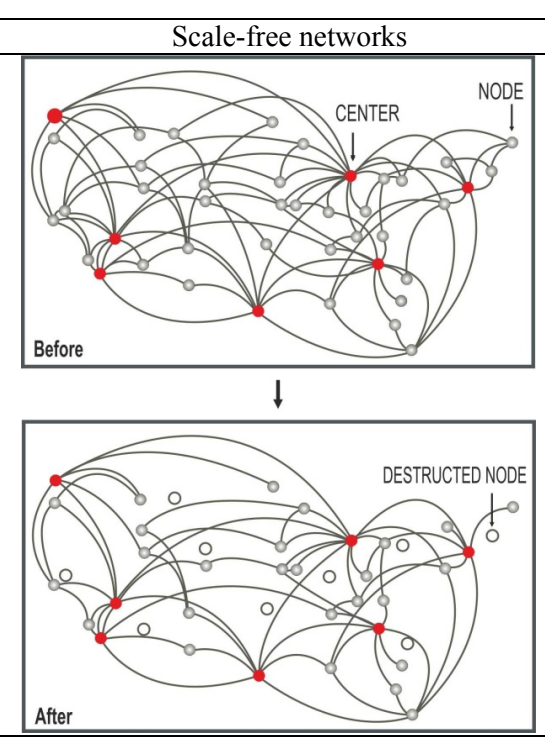

Huge sensitivity to the deliberate exclusion of centers from the network structure - these networks are very sensitive to attacks orgared intention lly at a given point - the network center. Intentional attack on several centers can lead to complete network disruption and structural disfunction.

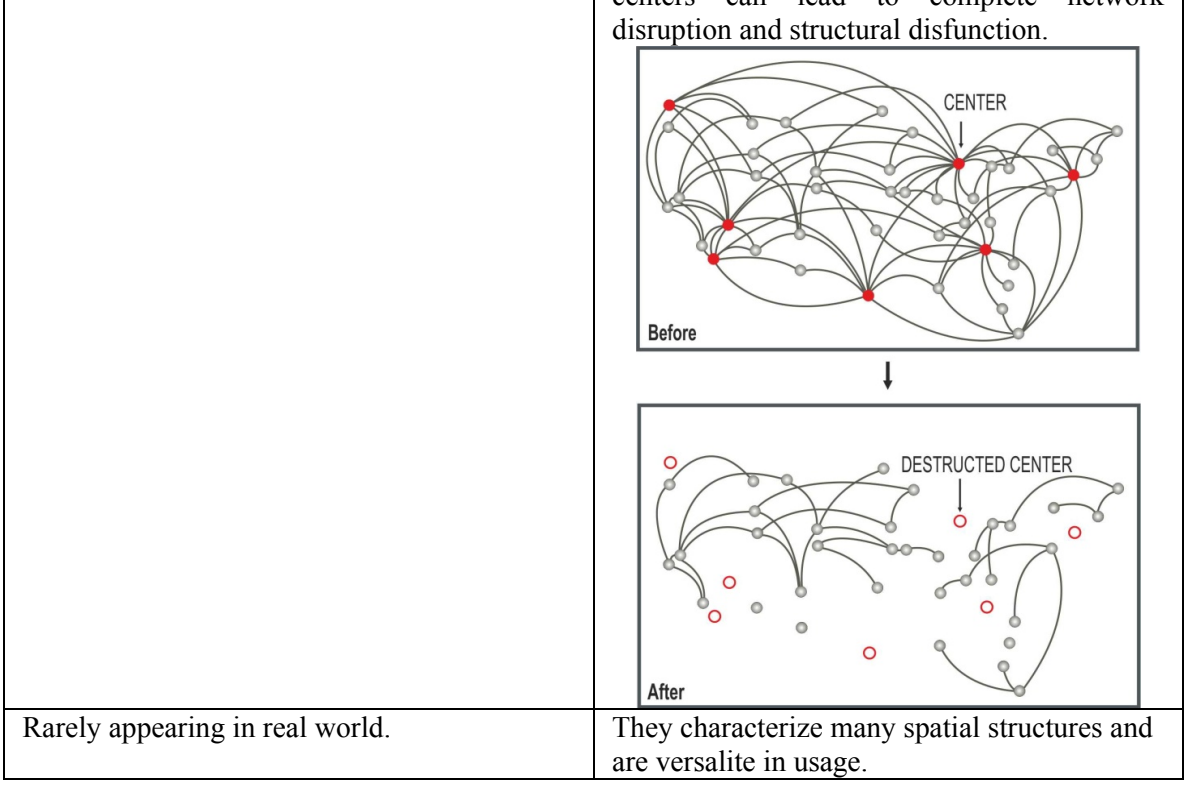




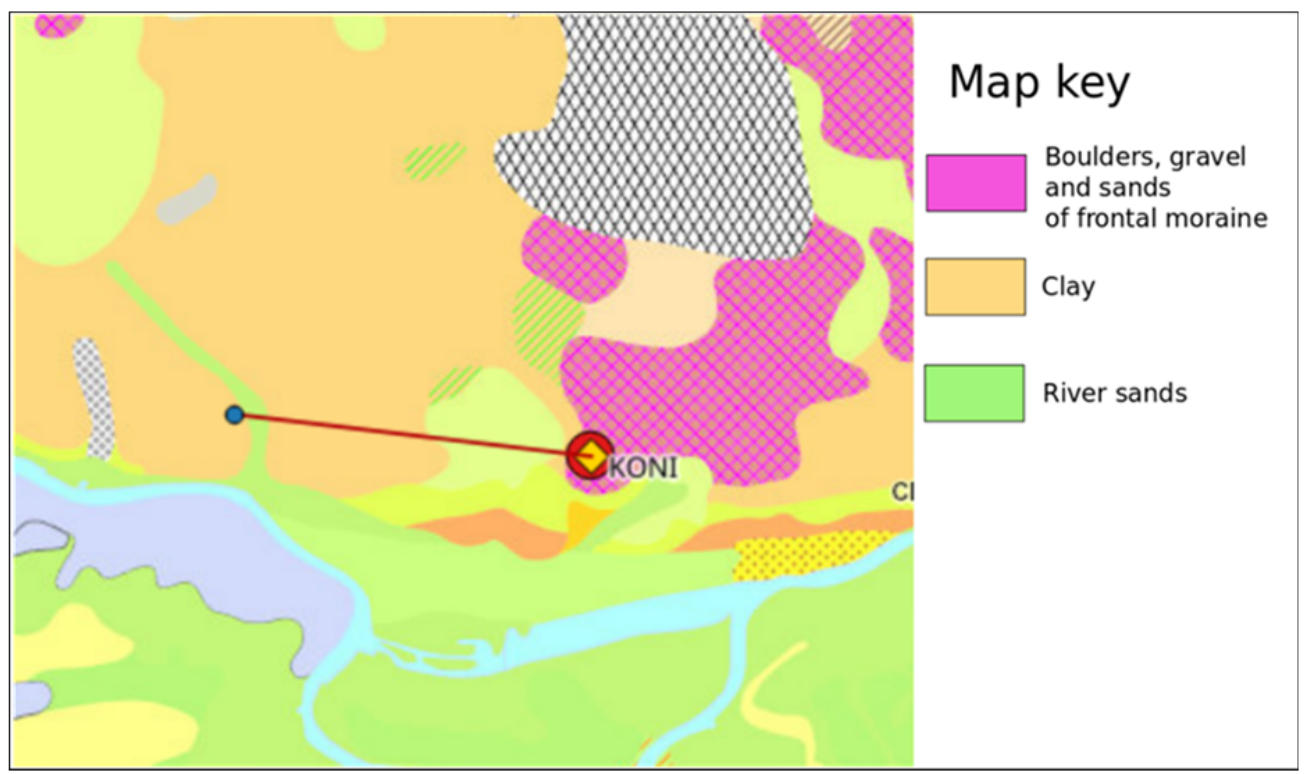

Fig. 11 Pseudo-nodal point on the detailed geological map.

Source: own elaboratin on the basis of WMS service:

http://cbdgmapa.pgi.gov.pl/arcgis/services/kartografia/smgp50k/MapServer/WMSServer.

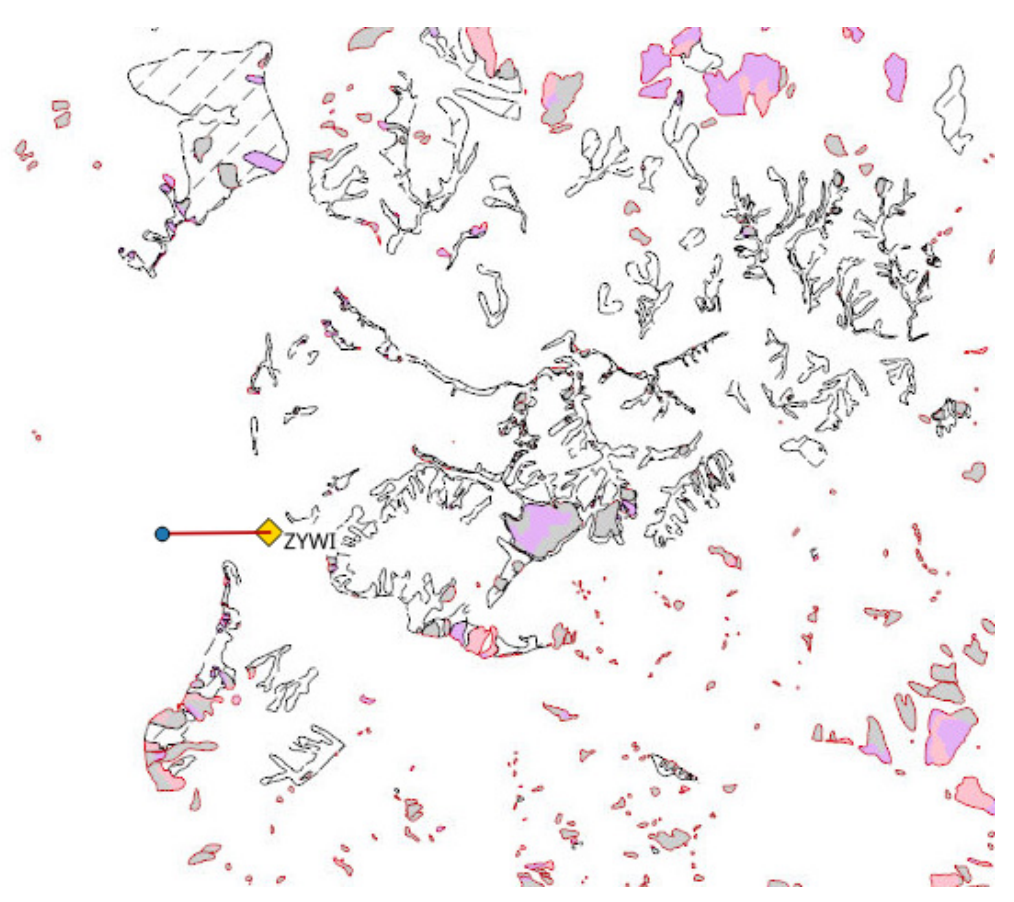

Fig. 13 Pseudo-nodal point on the site of the landslides.

Source: own elaboration on the basis of WMS service:

http://cbdgmapa.pgi.gov.pl/arcgis/services/geozagrozenia/sopo_obszary/MapServer/WMSServer 